\title{
Analysis of differences in variables related to health and safety according to the employment type of Korean workers
}

\author{
Jung $\mathbf{H}^{1}$, Han $\mathbf{S}^{2}$
}

${ }^{1}$ College of Nursing, Kyungpook National University. 680, Gukchaebosang-ro, Jung-gu, Daegu 41944, Korea, ${ }^{2}$ Department of Emergency Medical Technology, Kyungil University. Gamasilgil Hayangeup, Gyeongbuk 38428,

$$
\text { Korea }
$$

\section{Abstract}

Introduction: The purpose of this study was to understand the differences in variables related to health and safety according to the employment type of Korean workers, specifically to identify the differences by employment type on in health status, the likelihood of wearing protective gear when working, access to manuals on emotional expression, and access to information on risk factors related to health and safety.

Methods: The secondary data of four items on employment type, health type of workers and safety among the 5th Korean Working Condition Survey conducted in 2017 in Korea was used in this study. The data of workers were processed by using SPSS/WIN 23.0 Program and R 3.1.2, and demographic characteristics were quantified as frequency and percentage.

Results: A total of 30,300 employed people were surveyed. The result shows that part-time workers have poorer health than full-time workers (c2 = 540.7155, $p<0.05$ ), insufficiently wore protective gear (c2 = 24.8702, $p<0.05$ ), had insufficient access to manuals on emotional expression (c2 $=27.7612, p<0.05)$ and lacked information about risk factors $(c 2=185.0082, p<0.05)$.

Conclusion: Health and safety manager will need to have education and consultation, development of manual and perform an early intervention to improve safety environment as primary health care providers by understanding factors related to health and safety of part-time workers.

Key words: Employment, Health and Safety, Korea, Work

\section{INTRODUCTION}

n Korea, the number of part-time workers who work $<35$ h/week more than doubled from 200,000 in 2010 to 560,000 in 20201 . However, the minimum wage in Korea has also increased by $27.3 \%$ over the past 2

DOI: https://doi.org/10.3126/ijosh.v12i1.41030

Conflicts of interest: None

Supporting agencies: None

Date of submission: 28.07.2021

Date of acceptance: 01.11.2021

Date of publication: 01.01.2022

\section{Corresponding Author}

Dr. Seung-Woo Han Ph.D.,

Assistant professor, Department of Emergency Medical Technology,

Kyungil University. Gamasilgil Hayangeup, Gyeongbuk 38428, Korea

E-mail: swhan@kiu.ac.kr

Tel:82-53-600-5691, Fax:82-53-600-5699

ORCID: https://orcid.org/0000-0001-9144-3285 years, so the number of high-quality part-time jobs is decreasing as labor expenses increase..$^{1,2}$

Part-time work in Korea is a kind of irregular job; it has lower wages and lower social insurance benefits compared to regular work. ${ }^{3}$ Part-time work in Korea is very unstable, with a lack of in-company education and training, and a short period of continuous service. As a result, part-time workers in Korea are treated as cheap and replaceable, and the social opinion of these workers is generally negative ${ }^{4}$. An inferior employment environment refers to a small-scale workplace that is vulnerable to industrial accidents and cannot manage safety and health. ${ }^{1}$ Inferior employment environment can have bad influences on the physical and mental health of part-time workers. ${ }^{2}$ They can also experience stress, feelings of inferiority, depression and anxiety at

\section{(c) (7) (8)}

This journal is licensed under a Creative Commons AttributionNon Commercial 4.0 International License. 
work and in daily life. ${ }^{4,5}$ Part-time workers usually have a low level of job satisfaction due to poor job conditions and recognition of low socio-economic status. ${ }^{6,7}$ which might lead to experience a low level of life satisfaction ${ }^{4}$. Irregular part-time workers have a relatively high likelihood of being exposed to various risk factors such as non-wearing of safety equipment, irregular overtime, dangerous workplaces thus emphasizing that irregular employment also has a negative influence on industrial health safety 8 . In addition, part-time workers should be provided with appropriate opportunities for emotional expression to express their grievances about their working environment, which is often impossible in reality ${ }^{6}$.

Previous research suggested that the health status of individuals along with the presence of appropriate wages and labor contract periods should be guaranteed, industrial accidents should be prevented by appointing a person in charge of safety and medicine. ${ }^{9}$ Although industries in Korea often perform formal safety and health activities but it is under taken to meet the legal requirements rather than the safety and health of the workers. Therefore, these companies should have active health facilities to manage health and safety and to promote a pleasant working environment for parttime workers. In addition, national level guidelines for the management of safety and health can be used in the industrial fields should be developed.

As part of job creation, Korea has recognized part-time work as a method that can increase the flexibility of the labor market, improve the quality of people's lives, solve the problems of an aging population, low birthrate and unemployment, and increase leisure time and opportunities for self-realization. Therefore, in 2014, the government enacted changes in employment conditions and promoted the protection of part-time workers and employees to expand the number of qualified part-time jobs ${ }^{2}$. Korea has been trying to expand the scope of health and safety managers to change the working environment of all its workers. ${ }^{10,11}$ Therefore, this study will provide the basic data on relevant factors such as health and safety of Korean workers so that health and safety managers in the community can promote the health and safety of parttime workers. The purpose of this study is to identify the differences between factors related to health and safety according to the employment type of Korean workers; the specific hypotheses are as follows. Hypothesis 1. Part-time workers will have inferior health compared to full-time workers. Hypothesis 2. Part-time workers will less likely to wear protective gear while working compared to full-time workers. Hypothesis 3. Part-time workers will lack access to manuals on emotional expression compared to full-time workers. Hypothesis 4. Part-time workers will be less informed of risk factors compared to full-time workers.

\section{METHODS}

This study is descriptive research to identify the differences between factors related to health and safety according to the employment types.

The goal of the Korean Working Conditions Survey is to assess the overall work environment, such as employment type, employment status, job type, industry type, exposure to risk factors, and employment security for employed persons aged 15 and over nationwide benchmarking the European Working Conditions Surveys (EWCS) and the UK Labour Force Survey (LFS). ${ }^{12,13}$ The survey was developed based on the questionnaire items of EWCS for international comparison and employment status, occupation, and industry classification were modified according to the Korean situation(work patterns, employment types, occupation types, etc.). From July to November 2017, professional interviewers personally visited the households and completed CAPI (computer-assisted personal interviewing) using a tablet $\mathrm{PC}$ as a 1:1 interview. A total of 50,205 employed people were surveyed.

The Participants are the 5th Korean Working Conditions Survey (KWCS) conducted in 2017, and the respondents are employed aged 15 or older. ${ }^{14}$ Out of a total of 50,205 subjects, a final sample of about 30,300 subjects was collected except those fitting the exclusion criteria (Figure 1). Among the 50.205 workers collected, business owners, self-employed, and temporary leave workers were primarily excluded. Of the remaining 33,781 subjects, 3,481 samples with missing values were excluded, and a final sample of 30,300 workers was selected.

This survey was a modification of the original survey of European Working Conditions Survey (EWCS) conducted in Europe in 2015 and was provided in Korean and English languages. ${ }^{12}$ Publication right for major surveys belongs to Eurofound, the host organization of European Working Conditions Survey and Occupational Safety \& Health Research Institute 
has an independent publication right in Korea as a result of a Memorandum of Understanding with Eurofound. ${ }^{15}$ Two researchers selected four items related to employment types and health and safety of workers among a total of 73 items and used these four in the study. The final four items were selected in consideration of health and safety-related variables and statistical applicability.

How workers perceive their health as a whole was analyzed as (1) Very good (2) Good (3) Normal (4) Bad (5) Very bad based on the questionnaire 'How is your overall health?'.

Whether workers are allowed to express their emotions were analyzed as (1) Yes (2) No based on the questionnaire 'Do you have a standard (manual) for expressing emotions required by the company in relation to the performance of your job?'.

Whether workers are required to wear protective gear during work was analyzed as (1) Yes (2) No based on the questionnaire, 'Do you have to wear personal protective gear (safety helmet, safety gloves, mask, safety glasses, etc.)?.

Whether workers are provided with information on health and safety was analyzed as (1) Very well received (2) Well received (3) Not much received (4) Never received based on the questionnaire 'How well are you informed of 'health and safety risk factors related to your work?'.

The Korean Working Conditions Survey is operated by Statistics Korea National Approval Statistics (Approval No. 380002). This data is open to the Korea Occupational Safety and Health Agency. The data were used in this study with the permission of the Department of Policy and System Research in Occupational Safety \& Health Research Institute, and personal information of the subjects was not included in the data.

In addition, the data were used only for study and used for final analysis after the suitability of the survey had been verified by the Department of Policy and System Research in the Occupational Safety \& Health Research Institute.

Computerized statistics processing methods using SPSS/WIN 23.0 Program and R 3.1.2 were used for the collected data. The demographic characteristics of workers were processed by frequency and percentage. The differences in factors related to health type and safety of workers according to the employment types were processed using crossover analysis and chisquare test.

\section{RESULTS}

In terms of gender, males were the highest in full and part-time $81.0 \%, 80.3 \%$, respectively.

In terms of age, 40-52 years old were $33.4 \%, 53-65$ were $32.7 \%$, < 39 were $18.8 \%$, and > 65 were $15.1 \%$ in full time. However, 53-65 old years were 38.7\%, 40-52 years old were $29.4 \%,<39$ were $16.2 \%$, and > 65 were $15.7 \%$ in part-time. As for the academic background, high school graduate was the highest in full and part-time $41.1 \%, 38.3 \%$, respectively. Regarding the business type, $88.2 \%$ and $76.3 \%$ of full and part-time workers, respectively, who answered "private". According to the subjective health condition, $56.3 \%$ and $57.1 \%$ of full and part-time workers, respectively, reported "good". In terms of satisfaction on the working environment, $70.8 \%$ and $68.2 \%$ of full and part-time workers, respectively, who answered: "satisfied". Regarding the employment status of participants, $49.6 \%$ and $37.4 \%$ of full and part-time workers, respectively, said: "regular workers" (Table 1).

Hypothesis 1. Part-time workers will have inferior health to full-time workers. As a result of the crossover test, the $\mathrm{X}^{2}$ statistic was 540.7115 , with a $p$-value $<0.05$. Therefore, hypothesis 1 was supported at the $5 \%$ of the significance level. Part-time workers $(0.065)$ were found to have inferior health compared to full-time workers (0.019) (Table 2).

Hypothesis 2. Part-time workers will be less likely than full-time workers to wear protective gear while working. As a result of the crossover test, the $X^{2}$ statistic was 24.8702, with a $p$-value $<0.05$. Therefore, hypothesis 2 was supported at the $5 \%$ of the significance level. Part-time workers (0.749) were less likely than full-time workers to wear protective gear while working (0.712) (Table 3).

Hypothesis 3. Part-time workers will lack access to manuals on emotional expression compared to full-time workers. As a result of the crossover test, the $\mathrm{X}^{2}$ statistic was 27.7612 , with a $p$-value $<0.05$. Therefore, hypothesis 3 was supported at the $5 \%$ of the significance level. Part-time workers (0.811) lack access to manuals on emotional expression compared to full-time workers (0.845) (Table 4). 
Hypothesis 4. Part-time workers will be less informed of risk factors compared to full-time workers. As a result of the crossover test, the $X^{2}$ statistic was 185.0082, with a $p$-value $<0.05$. Therefore, hypothesis 4 was supported at the $5 \%$ of the significance level. Part-time workers (0.291) were found to be less informed of risk factors on health and safety while working, compared to fulltime workers (0.238) (Table 5).

Table 1: Sociodemographic Characteristics of the Participants $(N=30,300)$

\begin{tabular}{|c|c|c|c|}
\hline Characteristic & & $\begin{array}{c}\text { Full-Time } \\
\mathrm{N}(\%)\end{array}$ & $\begin{array}{l}\text { Part-Time } \\
\mathrm{N}(\%)\end{array}$ \\
\hline \multirow{2}{*}{ Gender } & Male & $20,911(81.0)$ & $3,729(83.2)$ \\
\hline & Female & $4,906(19.0)$ & 754(16.8) \\
\hline \multirow{4}{*}{ Age } & $\leq 39$ & $4,854(18.8)$ & $726(16.2)$ \\
\hline & $40-52$ & $8,623(33.4)$ & $1,318(29.4)$ \\
\hline & $53-65$ & $8,442(32.7)$ & $1,735(38.7)$ \\
\hline & $>65$ & $3,898(15.1)$ & 704(15.7) \\
\hline \multirow{6}{*}{ Academic background } & Under elementary school graduate & $671(2.6)$ & $170(3.8)$ \\
\hline & Elementary school graduate & $1,394(5.4)$ & $390(8.7)$ \\
\hline & Middle school graduate & $2,343(9.0)$ & $542(12.1)$ \\
\hline & High school graduate & $10,611(41.1)$ & $1,717(38.3)$ \\
\hline & University graduate & $10,326(40.0)$ & $1,641(36.6)$ \\
\hline & Over graduate school & $472(1.9)$ & $23(0.5)$ \\
\hline \multirow{5}{*}{ Business type } & Private & $22,700(88.2)$ & $3,421(76.3)$ \\
\hline & Public & $1,652(6.4)$ & 618(13.8) \\
\hline & Private - public & $542(2.1)$ & 255(5.7) \\
\hline & Nonprofit organization & $697(2.7)$ & $139(3.1)$ \\
\hline & Others & $226(0.6)$ & $50(1.1)$ \\
\hline \multirow{5}{*}{$\begin{array}{l}\text { Subjective health } \\
\text { condition }\end{array}$} & Very good & $2,375(9.2)$ & $376(8.4)$ \\
\hline & Good & $14,535(56.3)$ & $2,560(57.1)$ \\
\hline & Normal & $7,409(28.7)$ & $1,089(24.3)$ \\
\hline & Bad & $1,265(4.9)$ & $287(6.4)$ \\
\hline & Very bad & $233(0.9)$ & 171(3.8) \\
\hline \multirow{4}{*}{$\begin{array}{l}\text { Satisfaction on working } \\
\text { environment }\end{array}$} & Very satisfied & $1,084(4.2)$ & $166(3.7)$ \\
\hline & Satisfied & $18,278(70.8)$ & $3,057(68.2)$ \\
\hline & Not satisfied & $5,757(22.3)$ & 1,071(23.9) \\
\hline & Very not satisfied & $698(2.7)$ & $189(4.2)$ \\
\hline \multirow{4}{*}{ Employment status } & Regular workers & $12,805(49.6)$ & $1,677(37.4)$ \\
\hline & Temporary workers & $3,124(12.1)$ & $1,201(26.8)$ \\
\hline & Daily workers & $1,936(7.5)$ & $4287(5.1)$ \\
\hline & Others & $7,952(30.8)$ & $1,318(30.7)$ \\
\hline
\end{tabular}

Table 2: Employment types and overall health condition of workers

\begin{tabular}{cccccccc}
\hline & & Very good & Good & Normal & Bad & Very bad & Row Total \\
\hline & $(1)$ & 2824 & 16296 & 6320 & 488 & 29 & 25957 \\
Full-time & $(2)$ & 0.763 & 14.144 & 18.104 & 43.841 & 0.114 & \\
& $(3)$ & 0.109 & 0.628 & 0.243 & 0.019 & 0.001 \\
& $(4)$ & 0.872 & 0.883 & 0.813 & 0.636 & 0.806 \\
& $(5)$ & 0.093 & 0.538 & 0.209 & 0.016 & 0.001
\end{tabular}




\begin{tabular}{cccccccc} 
& $(1)$ & 415 & 2153 & 1454 & 279 & 7 & 4308 \\
Part-time & $(2)$ & 4.599 & 85.224 & 109.081 & 264.158 & 0.687 & \\
& $(3)$ & 0.096 & 0.500 & 0.338 & 0.065 & 0.002 & \\
& $(4)$ & 0.128 & 0.117 & 0.187 & 0.364 & 0.194 & \\
Column Total & $(5)$ & 0.014 & 0.071 & 0.048 & 0.009 & 0.000 & \\
& & 3239 & 18449 & 7774 & 767 & 36 & 30265 \\
\hline
\end{tabular}

Pearson's Chi-squared test, $X^{2}=540.7155, p=.001$

(1) Observed frequency: Actual number of samples

(2) Expected ratio: Total observation frequency divided by the number of categories

(3) Ratio for line: Values in observations divided by the row total. In the interpretation of the results, the higher the results, the higher the probability of occurrence.

(4) Ratio for row: Percentage of observations across rows

(5) Ratio among the whole: Total divided by the observation

Table 3: Employment types and degree of wearing personal protectors (safety helmet, safety gloves, masks, safety glasses, etc.) and protective gears

\begin{tabular}{lcccc}
\hline & Yes & No & Row Total \\
\hline \multirow{4}{*}{ Full-time } & $(1)$ & 7469 & 18481 & 25950 \\
& $(2)$ & 2.539 & 1.000 & \\
& $(3)$ & 0.288 & 0.712 & 4305 \\
Part-time & $(4)$ & 0.874 & 0.851 & \\
& $(5)$ & 0.247 & 0.611 & 3225 \\
\\
& $(1)$ & 1080 & 6.028 & 0.749 \\
Column Total & $(2)$ & 0.251 & 0.149 & 30255 \\
\hline
\end{tabular}

Pearson's Chi-squared test, $X^{2}=24.8702, p=.001$

(1) Observed frequency, (2) - Expected ratio, (3) - Ratio for line, (4) - Ratio for row, (5) Ratio among the whole

Table 4: Employment types the presence of regulations (manual) on emotional expression required by the company in relation to job performance

\begin{tabular}{|c|c|c|c|c|}
\hline & & Yes & No & Row Total \\
\hline \multirow{5}{*}{ Full-time } & (1) & 4895 & 20999 & \multirow{5}{*}{25894} \\
\hline & (2) & 3.213 & 0.726 & \\
\hline & (3) & 0.189 & 0.811 & \\
\hline & (4) & 0.880 & 0.853 & \\
\hline & (5) & 0.162 & 0.696 & \\
\hline \multirow{5}{*}{ Part-time } & (1) & 665 & 3616 & \multirow{5}{*}{4281} \\
\hline & (2) & 19.433 & 4.390 & \\
\hline & (3) & 0.155 & 0.845 & \\
\hline & (4) & 0.120 & 0.147 & \\
\hline & (5) & 0.022 & 0.120 & \\
\hline \multirow{2}{*}{ Column Total } & & 5560 & 24615 & \multirow[t]{2}{*}{30175} \\
\hline & & 0.184 & 0.816 & \\
\hline
\end{tabular}

Pearson's Chi-squared test, $X^{2}=27.7612, p=.001$

(1)- Observed frequency, (2) - Expected ratio, (3) - Ratio for line, (4) - Ratio for row, (5) - Ratio among the whole 
Table 5: Employment types and how workers well received the information on 'risk factors of health and safety'

\begin{tabular}{|c|c|c|c|c|c|c|}
\hline & & $\begin{array}{l}\text { y well } \\
\text { eived }\end{array}$ & $\begin{array}{c}\text { Well } \\
\text { received }\end{array}$ & $\begin{array}{l}\text { Not much } \\
\text { received }\end{array}$ & $\begin{array}{c}\text { Never } \\
\text { Received }\end{array}$ & Row Total \\
\hline \multirow{5}{*}{$\begin{array}{l}\text { Full- } \\
\text { Time }\end{array}$} & (1) & 4614 & 13065 & 6138 & 2018 & \multirow{5}{*}{25835} \\
\hline & (2) & 4.875 & 3.421 & 6.098 & 11.858 & \\
\hline & (3) & 0.179 & 0.506 & 0.238 & 0.078 & \\
\hline & (4) & 0.886 & 0.872 & 0.831 & 0.795 & \\
\hline & (5) & 0.153 & 0.434 & 0.204 & 0.067 & \\
\hline \multirow{5}{*}{$\begin{array}{l}\text { Part- } \\
\text { Time }\end{array}$} & (1) & 591 & 1916 & 1244 & 521 & \multirow{5}{*}{4272} \\
\hline & (2) & 29.481 & 20.689 & 36.877 & 71.709 & \\
\hline & (3) & 0.138 & 0.449 & 0.291 & 0.122 & \\
\hline & (4) & 0.114 & 0.128 & 0.169 & 0.205 & \\
\hline & (5) & 0.020 & 0.064 & 0.041 & 0.017 & \\
\hline \multirow{2}{*}{ Column Total } & & 205 & 14981 & 7382 & 2539 & \multirow[t]{2}{*}{30107} \\
\hline & & 173 & 0.498 & 0.245 & 0.084 & \\
\hline
\end{tabular}

Pearson's Chi-squared test, $X^{2}=185.0082, p=.001$

(1) - Observed frequency, (2) - Expected ratio, (3) - Ratio for line, (4) - Ratio for row, (5) - Ratio among the whole

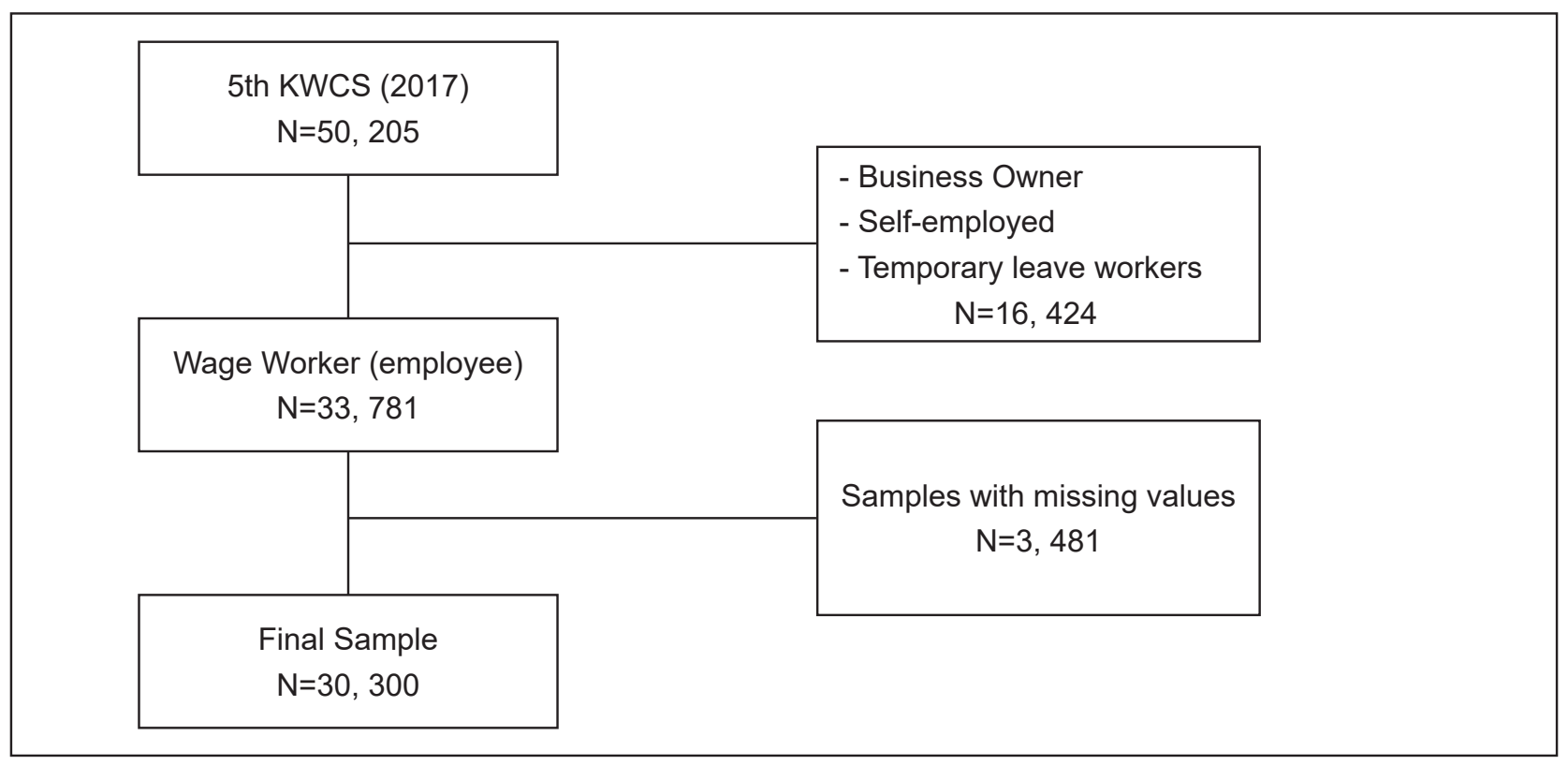

Figure 1: The Sample Selection Process.

\section{DISCUSSION}

This study identified the differences between factors related to health and safety according to the employment types of Korean workers by using the secondary data of the 5th Korean Working Condition Survey presented by the Korea Occupational Safety \& Health Agency in 2017. In particular, this study focused on identifying factors related to health and safety of part-time workers, to contribute to health equity and the creation of a safe working environment. The results of crossover analysis on the employment types and overall health condition showed that full-time workers $(0.628)$ had better health than part-time workers (0.500). The proportion of workers who responded that their health condition was poor was higher among part-time (0.065) workers than among full-time workers (0.019). Previous studies suggested that part-time workers often work in unstable work and inferior working environments due to the unstable employment type. ${ }^{4,8}$ As a result, they have a high possibility of being exposed to various diseases due to the various job stresses, hierarchical working conditions and inappropriate compensation. In particular, they show symptoms of poor physical health in addition to subjective health conditions such as high stress. ${ }^{6,16}$ Therefore, measures must be established at 
institutional level to promote the health equity of the two types of employment. Employers should be able to help workers use government-provided free programs, such as community counseling centers and workers should be able to make good use of them.

The study results showed that more full-time workers $(0.288)$ than part-time workers $(0.251)$ wore protective gear while working. In a previous precedent study, parttime workers were found to have more possibilities than full-time workers to be exposed to environmental risks such as vibration, noise, high temperature, inhalation and skin contact with chemicals, and the proportion who did not wear protective gear was higher for parttime $(12.4 \%)$ than for full-time $(9.9 \%)$ workers. ${ }^{17}$ A dangerous working environment can lead to industrial accidents, so wearing protective gear is considered to have a significant positive correlation with the health and safety of workers. Recently, the death of a 19-year-old part-time worker during the installation of a screen door had become big news in Korea, so under the 'Act on the prevention of outsourcing of danger' regarding the health and safety of irregular workers was then proposed..$^{18}$ As a result, each department is being asked to establish various legal devices by revision of the Occupational Safety and Health Acts. Through continuous monitoring and anonymous bulletin boards, the government is showing concerns about the fair payment of wages for part-time workers, the use of safety equipment, discrimination and verbal abuse etc. However, part-time workers are still often more likely to be exposed to the risky environments and to not wear protective gear compared to full-time workers in the actual field. Therefore, it is believed that the government will need regular monitoring of the wearing of safety equipment.

The study results showed that part-time workers (0.115) had less access to manuals on emotional expression than full-time workers (0.189). Workers whose job is to interact with people can have a significantly high rate of psychological maladjustment such as depression, compared to other occupational groups. ${ }^{19}$ Such labor has a high work burnout rate and low job satisfaction. ${ }^{20}$ In particular, the results of a survey conducted by Korea Research Institute for Vocational Education \& Training (2017) for 203 occupations and 5,667 workers were: PR assistant (4.60/5.0), fast-food clerk (4.39/5.0) and telemarketer (4.35/5.0) among workers who work directly with people, and these were mainly confirmed by part- time workers. ${ }^{21}$ Recently in Korea, interest in the quality of life such as well-being, health promotion and prevention of disease are increasing and the choice of the occupation with increasing frequency based on the pursuit of happiness than of pay. ${ }^{22}$ However, many aspects of the working environment and work satisfaction of part-time workers parts remain to be improved. In particular, excessive psychological stress such as emotional expression is considered to have a significant influence on the health and well-being of part-time workers. Therefore, the government should understand part-time workers and establish institutional measures. Furthermore, the government should be able to support the development of an emotional expression manual for part-time workers.

The study results showed that full-time workers $(0.506)$ responded that they better received the information on risk factors related to health and safety than part-time workers (0.449), and part-time workers $(0.238)$ received less information than full-time workers (0.291). Appropriate provision of information related to health may improve the quality of life and lower the incidences of depression and anxiety. ${ }^{23}$ Previous study had also suggested providing appropriate information results in improved maintenance of health and recognition of safety by workers. ${ }^{24}$ However, the provision of such information was less appropriate for part-time workers than for full-time workers, so appropriate measures should be developed. Recently, the Occupation Safety and Health Act were revised in January 2019 in Korea, and the workplaces stated that they will provide workers with information on safety and health. ${ }^{25}$ The Korean government is making a best effort for the health and safety of workers and attempting to establish its measure quickly. However, the information provided is less adequate for part-time workers than or full-time workers, so workplaces should be monitored to determine whether it is good at providing information to part-time workers. Therefore, government and employers should understand the information provided on risk factors of health and safety beyond simple monitoring of the health condition of workers and should help to improve the relevance of the working environment.

This study is meaningful as it highlights the urgency to improve the work environment of part-time workers, and the appropriate roles of community nurses by analyzing the differences in the working environment of full-time and part-time workers. 
However, this study has limitations to identify various factors on the health and safety of workers in detail, because it is a cross-sectional study that used the Working Condition Survey. Further study should identify additional practical and multilateral factors in the health and safety of workers, and use this information to develop plans by which part-time workers can work in a safe environment without any discrimination. In future research, it will be important to compensate for the shortcomings of this study and achieve gender balance.

\section{CONCLUSION}

This study determined that compared to full-time workers, part-time workers have an inferior overall health condition, are less likely to wear protective gear while working, have less access to manuals on emotional expression, and are provided with less information about risk factors related to health and safety.

These results suggest that community nurses as primary health care providers should have education and consultation, to develop manuals and perform an early intervention to improve the safe environment by understanding factors related to the health and safety of part-time workers. In addition, the government should establish an Employment Act to improve the working environment of part-time workers and to prepare a legal and institutional system.

9. Lyonette C, Baldauf B, Behle H. 'Quality'Parttime Work: A Review of the Evidence. London: Government Equalities Office; 2010 Mar.

10. Kang, S.J.; Kim, I.S. Development of the Korean nursing profession with changes in its legal basis. Int J Nurs Clin Pract. 2016, 3, 165-69. DOI:10.15344/2394-4978/2016/165

11. Yoon SJ, Lin HK, Chen G, Yi S, Choi J, Rui Z. Effect of occupational health and safety management system on work-related accident rate and differences of occupational health and safety management system awareness between managers in South Korea's construction industry. Safety and health at work. 2013 Dec 1;4(4):201-9.

12. European Working Conditions Surveys (EWCS) https://www.eurofound.europa.eu/surveys/ european-working-conditions-surveys-ewcs

13. Office of National Statistics. UK Labour Force Survey (LFS). UK. [ Internet] Available from:https:// www.ons.gov.uk/surveys/information for households and individuals household and individual surveys/ labour force survey\#: : text=The $\% 20$ Labour $\% 20$ Force $\% 20$ Survey\%20(LFS, measures $\% 20$ of $\% 20$ employment\%20and\%20unemployment.

14. Welcome to the Occupational Safety and Health Research Institute(OSHRI). 5th Korean Working Conditions Survey (KWCS). [Internet] Available from : https://oshri.kosha.or.kr/eoshri/about/greetings.do

15. Eurofound, Occupational Health and Safety. [Internet]. Available from : https://www.eurofound. europa.eu/

16. Nakamura $M$, Toyama $\mathrm{Y}$, Nishiwaki $\mathrm{Y}$, Ushida T. Prevalence and characteristics of chronic musculoskeletal pain in Japan. Journal of orthopaedic science. 2011 Jul 1;16(4):424-32.

8. Goh J, Pfeffer J, Zenios S. Exposure to harmful workplace practices could account for inequality in life spans across different demographic groups. Health Affairs. 2015 Oct 1;34(10):1761-8. 
17. Jung, Y.H. Analysis of correlation between types of employment and industrial accident occurrence through "labor environment survey" (Unpublished master's thesis). The University of Ajou, Suwon, Gyeonggi-do, South Korea 2017.

18. Kim, D.G.; Kim, J.S. 'Kim Yong-Kyun act' and measures to cope with industrial safety in Gyeonggi Province. Issue \& Analysis. 2019;1-26.

19. Yoon SL, Kim JH. Job-related stress, emotional labor, and depressive symptoms among Korean nurses. Journal of Nursing Scholarship. 2013 Jun;45(2):16976.

20. Lee $\mathrm{YH}$, Chelladurai P. Emotional intelligence, emotional labor, coach burnout, job satisfaction, and turnover intention in sport leadership. European Sport Management Quarterly. 2018 Aug 8;18(4):393412.

21. Korea Research Institute for Vocational Education \& Training.[Internet] 2017.Available from :https://www. krivet.re.kr/eng/eu/index.jsp
22. Rudolf R. Changing paradigms in measuring national well-being: How does Korea rank "beyond GDP"? Asian Social Work and Policy Review. 2020 Jun;14(2):118-21.

23. Husson O, Mols F, Van de Poll-Franse LV. The relation between information provision and healthrelated quality of life, anxiety and depression among cancer survivors: a systematic review. Annals of Oncology. 2011 Apr 1;22(4):761-72.

24. Szarmach $A$, Piskunowicz $M$, Świętoń $D$, Muc A, Mockałło G, Dzierżanowski J, Szurowska E. Radiation safety awareness among medical staff. Polish journal of radiology. 2015;80:57.

25. Korea Ministry of Employment and Labor. Act on the revision of the occupational safety and health act.[Internet] 2019 Aug. Available from https:// www.moel.go.kr/info/lawinfo/revision/view.do?bbs_ seq $=20190100642$ 